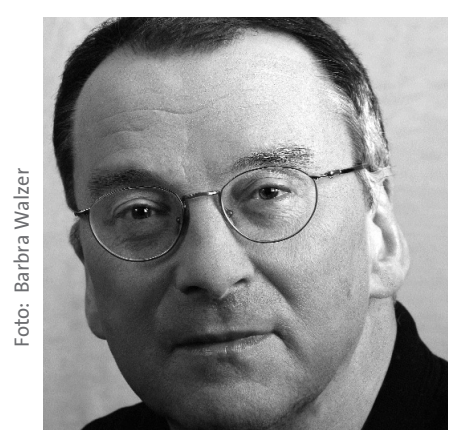

\title{
Von A nach B
}

»Heute back ich, morgen brau ich, / übermorgen hol ich der Königin ihr Kind. « Spätestens seit Rumpelstilzchen wissen wir um die Bedeutung vom richtigen Ablauf von Handlungen - und um die Störanfälligkeit von Prozessen. Der Beginn und der Zweck von Unternehmenstätigkeiten sind oft vorgegeben; das Prozessmanagement beschäftigt sich mit der Frage nach dem erfolgreichen und ressourcenschonenden Weg vom Anfang bis zum Ziel. Und da sich fast alle Variablen ändern können, bedarf es einer ständigen Optimierung von Prozessen, wie die Beiträge zum Titelthema in dieser Ausgabe von SOZIALwirtschaft darlegen. Mathias Konrad und Bernd Conrad zeigen in ihrem Praxisbeitrag, wie durch die systematische Analyse und Optimierung von Prozessen die aktuellen Strukturen in einer Organisation wie der Lebenshilfe Detmold vor dem Hintergrund der Kundenanforderungen überprüft wurden. Die Einheitlichkeit der Prozessabläufe wurde verbessert und das Wissen hierüber gesichert, damit es beispielsweise im Falle von Mitarbeiterwechseln nicht zu Einbrüchen kommen kann. Ganz nebenbei fördert die Einbindung der Mitarbeitenden in den Optimierungsprozess die Motivation, die Arbeitszufriedenheit und die Verbindlichkeit der Arbeitsergebnisse. Paul Brandl geht in seinem Artikel auf die Suche nach Einsparungspotenzialen in sozialwirtschaftlichen Unternehmen und nimmt dazu ebenfalls die Optimierung von Prozessen und Strukturen unter die Lupe. Helmut Kreidenweis legt in einem für dieses Heft von Markus Schmid zusammengefassten Vortrag dar, wie die Informationstechnik zur Steigerung der Wertschöpfung in sozialen Organisationen Erhebliches beitragen kann. Voraussetzung ist allerdings auch hier: Die Technik und ihr Einsatz müssen organisch in die Gestaltung von Geschäftsprozessen einbezogen sein.

Gerhard Pfannendörfer, Chefredaktion

E-Mail pfannendoerfer@nomos.de Internet http://www.sozialwirtschaft.nomos.de 